Etnográfica

Revista do Centro em Rede de Investigação em

Antropologia

vol. 21 (2) | 2017

Vol. 21 (2)

\title{
Escrito a partir da poltrona ou inveja do terreno
}

Writing from the armchair or envying the field

\section{Manuela Ribeiro Sanches}

\section{OpenEdition}

\section{Journals}

\section{Edição electrónica}

URL: https://journals.openedition.org/etnografica/4949

DOI: 10.4000/etnografica.4949

ISSN: 2182-2891

\section{Editora}

Centro em Rede de Investigação em Antropologia

\section{Edição impressa}

Data de publição: 1 junho 2017

Paginação: 413-436

ISSN: 0873-6561

\section{Refêrencia eletrónica}

Manuela Ribeiro Sanches, «Escrito a partir da poltrona ou inveja do terreno», Etnográfica [Online], vol. 21 (2) | 2017, posto online no dia 09 julho 2017, consultado o 09 fevereiro 2022. URL: http:// journals.openedition.org/etnografica/4949 ; DOI: https://doi.org/10.4000/etnografica.4949

\section{(c) (i) (9)}

Etnográfica is licensed under a Creative Commons Attribution-NonCommercial 4.0 International License. 


\section{Escrito a partir da poltrona ou inveja do terreno}

\section{Manuela Ribeiro Sanches}

O presente ensaio propõe uma viagem pelo tempo e pelo espaço, a revisitação de um percurso académico e teórico entre (narrativas de) viagem e antropologia, considerando o papel decisivo de ambas para se repensar disciplinas, epistemologias e os respetivos objetos e as suas fronteiras, introduzindo, igualmente, o elogio da nostalgia do distante, a partir do lugar imóvel onde este acaba sempre por ser narrado. O texto nada tem de autobiográfico, constituindo, antes, um pretexto para uma reflexão sobre a sedução e a necessidade da tarefa de comparação e de tradução que a antropologia ainda continua a representar.

PALAVRAS-CHAVE: literatura de viagens, antropologia e literatura, pós-colonialidade, tradução e comparação.

Writing from the armchair or envying the field - The present essay proposes a journey through time and space, revisiting an academic and theoretical trajectory between travel (narratives) and anthropology, considering the decisive role of both to rethink disciplines, epistemologies and the corresponding objects and borders, also introducing the praise of the nostalgia for the distant, ultimately always narrated from an immobile place. The text is not intended to be autobiographic, but rather offers a pretext to linger and reflect upon the seduction and necessity of the task of comparison and translation that anthropology still stands for.

KEYWORDS: travel literature, anthropology and literature, post-coloniality, translation and comparison.

SANCHES, Manuela Ribeiro (msanches@campus.ul.pt) - Faculdade de Letras da Universidade de Lisboa, Portugal. 


\section{ABERTURA: ANCORAGEM E RISCO, CULTURA E INVENÇÃO}

Gostaria de começar, como é habitual, pelos agradecimentos: ao Miguel Vale de Almeida, aos meus amigos antropólogos - e já são muitos -, que também desempenharam um papel neste percurso que irei descrever hoje. ${ }^{1}$ É um prazer e também um risco estar aqui, depois de ter aceitado o desafio para proferir a Aula Ernesto Veiga de Oliveira. O risco decorre de ir falar para especialistas, a partir de uma perspetiva exterior ao campo da antropologia, de notas escritas no conforto da poltrona, lugar de segurança e de ancoragem; mas com inveja do terreno, como elemento definidor do trabalho antropológico por excelência, na atenção àquilo que liga essas duas perspetivas - a da poltrona e a do terreno. Daí a necessidade de abordar, também, o tema da comparação, tradução entre perspetivas, disciplinas.

Começarei com algumas notas prévias que poderão, porventura, parecer um pouco abstratas, mas notas que são importantes para o argumento que irei desenvolver e que se prende com aquilo que constitui, para mim, a relevância da antropologia, os caminhos que com ela percorri, o que ela me trouxe.

Inaugural indica que algo se inicia, um novo ano letivo, uma nova fase da vida, no vosso caso, o de se tornarem antropólogos doutores ou de se tornarem antropólogos pela primeira vez. É o futuro que se abre à vossa frente, com os seus receios, sonhos, expectativas, riscos, novos continentes - permitam-me esta metáfora colonial - do saber e do terreno, mais próximos ou mais longínquos. Eu acabo de iniciar também uma nova fase, não de começo ou de futuro, mas de fim e de passado, depois de aposentada, estranha palavra, retirada nos meus aposentos, para, da minha poltrona, observar, revisitar a vida, o passado, passado que, por muito velhos que sejamos, nunca podemos desligar do futuro, que em vós vejo e adivinho e de que espero, também, fazer parte, pelo menos durante algum tempo.

Inaugural pode também indicar que começamos do zero, de uma folha em branco. Mas creio que não é exatamente assim, pois o inaugural não corresponde nunca a começar-se do zero, por muito que, em algumas circunstâncias, gostássemos que assim fosse. Estamos todos marcados pelos nossos passados, experiências, histórias individuais e coletivas, mais ou menos longas, pelos

1 Este texto foi inicialmente apresentado oralmente no dia 3 de outubro de 2016 como Aula Ernesto Veiga de Oliveira, organizada pelo Departamento de Antropologia do ISCTE - Instituto Universitário de Lisboa e dirigida especialmente aos novos alunos do curso de licenciatura em Antropologia. Quero dedicar esta aula inaugural, cujo tom oral mantive a fim de captar por escrito um momento muito agradável para mim, aos meus antigos alunos, sobretudo os alunos-antropólogos que frequentaram um seminário opcional com o título "Escrever entre Culturas" que lecionei no segundo semestre de 1997-98, decorridos precisamente 20 anos. A eles devo muito o que aqui escrevo, traduzo. Todos os possíveis equívocos são, contudo, da minha inteira responsabilidade. 
nossos usos e costumes, mais ou menos conscientes, em suma, pelas nossas culturas.

Mas isto não equivale a que tenhamos de nos limitar a repetir o existente, condenando qualquer capacidade - utópica - de nos reinventarmos, de querer as coisas de um modo diferente. O que nos antecede é um peso, é certo, mas também uma ancoragem, algo que nos dá segurança. Todavia, felizmente, o risco persiste - o que aprendi também com a antropologia -, dado o modo como inventamos permanentemente - muitas vezes sem nos darmos conta disso - as práticas culturais quotidianas herdadas, o peso de uma tradição, que todos, porém, de um modo ou outro, contribuímos para transformar. Cultura é, assim, muito mais do que aquilo que herdámos, pelo que, quando digo que não partimos do zero absoluto, significa que não estamos determinados por uma natureza biológica ou cultural que nos amarra a necessidades incontroláveis - à tradição, à língua, à nação, à hereditariedade, à "raça" -, pois somos nós que fazemos aquilo que designamos como cultura, lendo, interpretando (Geertz 1973), o mundo em que vivemos e que herdámos, transformando-nos e adaptando-nos, de muitas maneiras, a novos contextos. Nada de novo, portanto, que os antropólogos não saibam.

Mas, de um outro ponto de vista, o inaugural também nunca equivale ao zero, mesmo quando experimentamos a angústia, real, do início da escrita, da página em branco. Também, neste caso, nunca estamos a começar do nada, pois, como Said lembrou em Beginnings (1975), o começar nunca é um principiar absoluto. Tecemos os textos que escrevemos, do mesmo modo que lemos e praticamos cultura, sempre a partir de outros textos, de um guião, como se de uma língua que aprendemos, mais ou menos conscientemente, se tratasse, como se tivéssemos um texto para traduzir, do modo mais traiçoeiro possível, se quisermos ser fiéis a esse original. Este, por sua vez, mais não é do que um diálogo com textos, realidades existentes, contemporâneas e passadas, mesmo se se tratar de ficção científica ou mundos utópicos que nunca existiram.

Como Colombo precisou das Índias Orientais para encontrar, perceber - e não perceber - as Ocidentais, também nós carecemos desses suportes já existentes, fonte, é certo, também de preconceitos, de equívocos, de estereótipos.

Mas a verdade é que, sem eles, não nos conseguimos orientar, a aventura carece do quotidiano, do mesmo modo que, sem conceitos, não conseguimos organizar a experiência, ou melhor, o domínio do empírico, pois a experiência já pressupõe que se organizou minimamente essas impressões que, sem esses conceitos, se reduziriam a mero caos, meros fragmentos, sem correlação entre si. Ou seja, sempre ancoragem e risco, risco amortecido pelo que é preexistente, que não evita, porém, que inventemos; ou seja, vivemos sempre num plano perigosamente inclinado, numa corda bamba que nos pode salvar ou perder. Mas a vida é mesmo assim, não só na academia, um ato de equilibrismo. 


\section{TOTALIDADE E MULTIDISCIPLINARIDADE}

Passemos à inspiração que a antropologia me trouxe, o que poderia também enunciar, de um modo menos favorável, como a inveja do terreno, a que poderia chamar inveja do antropólogo (Foster 2005 [1996]).

Permitam-me um pequeno excurso, antes de abordar esta questão de um modo mais preciso.

Creio que já terão ouvido falar em Alexander von Humboldt (1769-1859). Saiu recentemente uma biografia, de resto de leitura muito agradável (Wulf 2015), que recupera o seu legado, para os nossos dias e para o grande público, vendo nele um precursor do ambientalismo atual, capaz de pensar os ecossistemas, geógrafo enciclopédico, que também foi crítico da escravatura, admirador da França revolucionária, que visitou, pouco depois do eclodir da Grande Revolução, com Georg Forster, de quem também, daqui a pouco, vos falarei brevemente. De resto, Alexander von Humboldt sempre preferiu Paris a Berlim, o que lhe provocou dissabores entre franceses e prussianos, servindo de intermediário, de tradutor, entre culturas, também entre a Europa e as Américas, amigo de Thomas Jefferson e de Simón Bolívar, que conheceu, ainda jovem e folião, na capital da revolução, antes de se tornar o fogoso nacionalista, o cientista alemão privando e correspondendo-se, e tendo aprendido muito, como Mary Louise Pratt salienta, com os seus colegas mexicanos, venezuelanos, a elite crioula para cuja América reinventada também contribuiu (Pratt 1992: 135-137). Mas não vos vou contar a biografia de Humboldt, leiam-na. ${ }^{2}$

Concentremo-nos, antes, na figura 1 . O que vemos? Um ancião numa vasta sala - a legenda diz-nos que é em Berlim, em Oranienburger Straße 67. Alexander von Humboldt vê-se agora reduzido à imobilidade, ao seu cadeirão - não se trata exatamente de uma poltrona -, onde recebe admiradores, compila escritos, o monumental Kosmos (Humboldt 1845-1862), ${ }^{3}$ sonho que

2 Relativamente ao modo como a biografia de Humboldt foi lida e narrada e à subjetividade que sempre assiste à reconstituição de uma vida, como sucede com as poucas linhas que a seguir àquela se dedicam, ver Rupke (2008). Para a ficção que essa biografia continua ainda a inspirar, ver Kehlmann (2005), uma ficção de leitura agradável, historicamente pouco rigorosa, mas de grande sucesso, e que deu origem ao filme com o mesmo título, de Detlev Buck, em 2012.

3 A vastíssima obra de de Alexander von Humboldt surge poucas vezes mencionada na bibliografia, mas inclui uma referência a uma das poucas respetivas versões em português, uma coletânea de textos (Humboldt 2007). Para obter as suas obras em várias versões, a maior parte escrita originalmente em francês, recomenda-se a consulta do site onde algumas obras estão acessíveis: < http://www.avhumboldt.net/index.php?page $=138>$. Mais relevante ainda é a página $<$ http://humboldt.hs-offenburg. de/?page_id $=186 \&$ \&lang $=$ en $>$ onde se reúnem ligações para as obras disponíveis online. Ver ainda a edição online das suas viagens no site da Academia das Ciências de Berlim/Brandeburgo em $<$ http://avh. bbaw.de/orinoco/ > , academia responsável, quando esta se encontrava na antiga RDA, pela edição crítica das suas obras, como sucedeu com as de Georg Forster. Sobre a receção de Humboldt nas antigas RDA e RFA durante os tempos da Guerra Fria, veja-se Rupke (2008). 


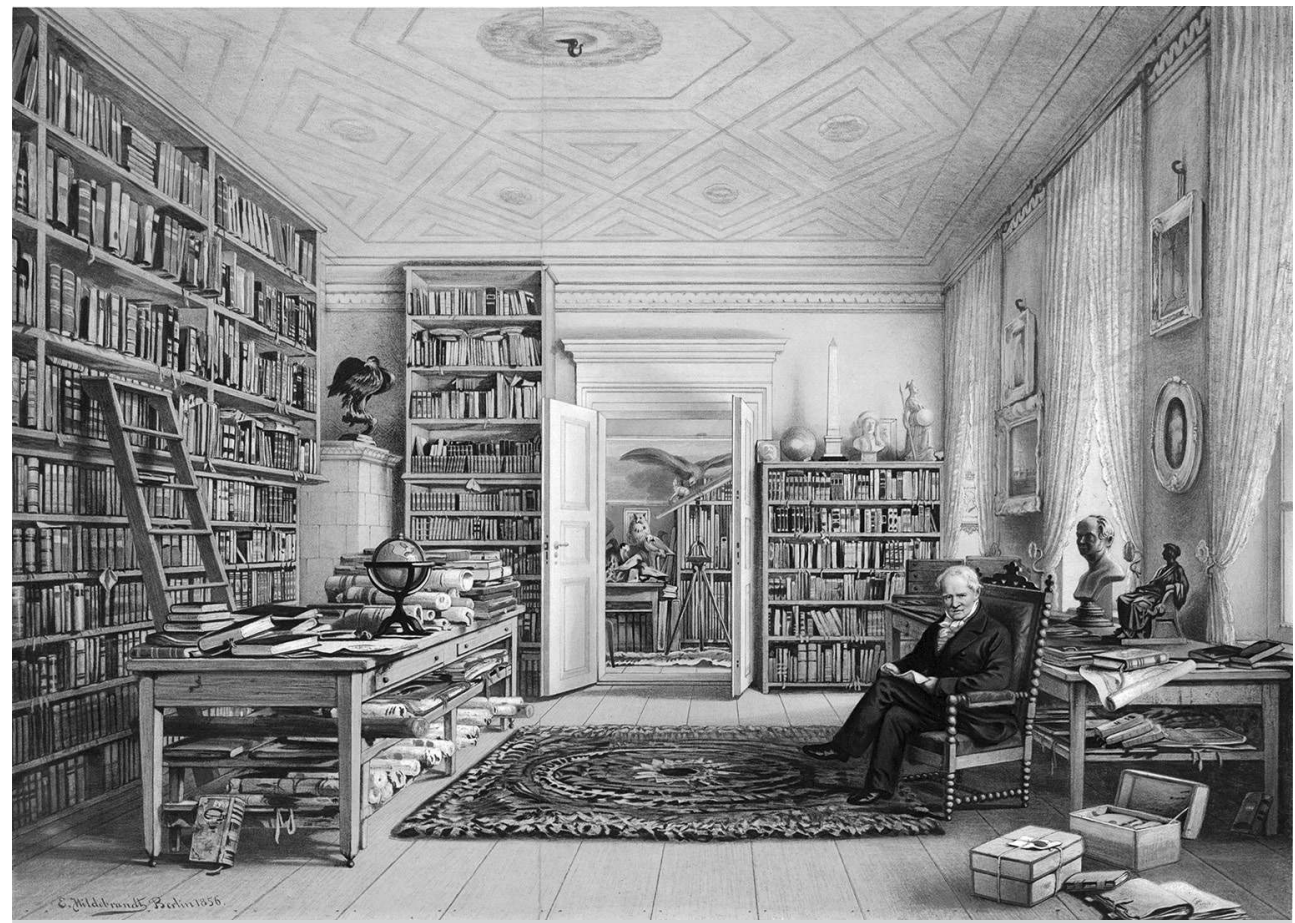

Figura 1 - "Alexander von Humboldt sentado na sua biblioteca na Oranienburger Straße 67 em Berlim", litografia (1856) segundo uma aguarela de Eduard Hildebrandt. (0) Kunstbibliothek, Staatliche Museen zu Berlin/Dietmar Katz/bpk.

perseguirá até aos seus últimos dias, inundado de cartas de admiradores, a que já não consegue responder. Observemos o ambiente, os objetos. Decerto, todos repararão em coisas diferentes. A mim, não por acaso, saltaram-me à vista a enorme biblioteca, o globo, os pássaros embalsamados, trazidos certamente das Américas, mas, depois, também, o busto do nosso lado direito. Alguém o reconhecerá?

A imagem seguinte (figura 2) leva-nos muitos anos atrás, quando Humboldt ainda era um jovem funcionário prussiano a trabalhar nas minas, interessando-se por fenómenos geológicos, mas também humanos, sociais, chamando, por exemplo, a atenção das autoridades para as condições de vida dos mineiros, recomendando o uso de máscaras para os proteger dos elementos poluentes.

Alexander von Humboldt encontra-se, agora, em Jena, cidade onde contactou com a atmosfera seleta, mas provinciana, da pequena corte do Grão-Ducado de Weimar, cujo soberano acolhera dois grandes vultos do cânone literário europeu, Johann Wolfgang von Goethe, que revemos no busto na sala do velho Humboldt (figura 1), bem como o seu companheiro de sempre, Friedrich Schiller, em cujo jardim o grupo confraterniza. 


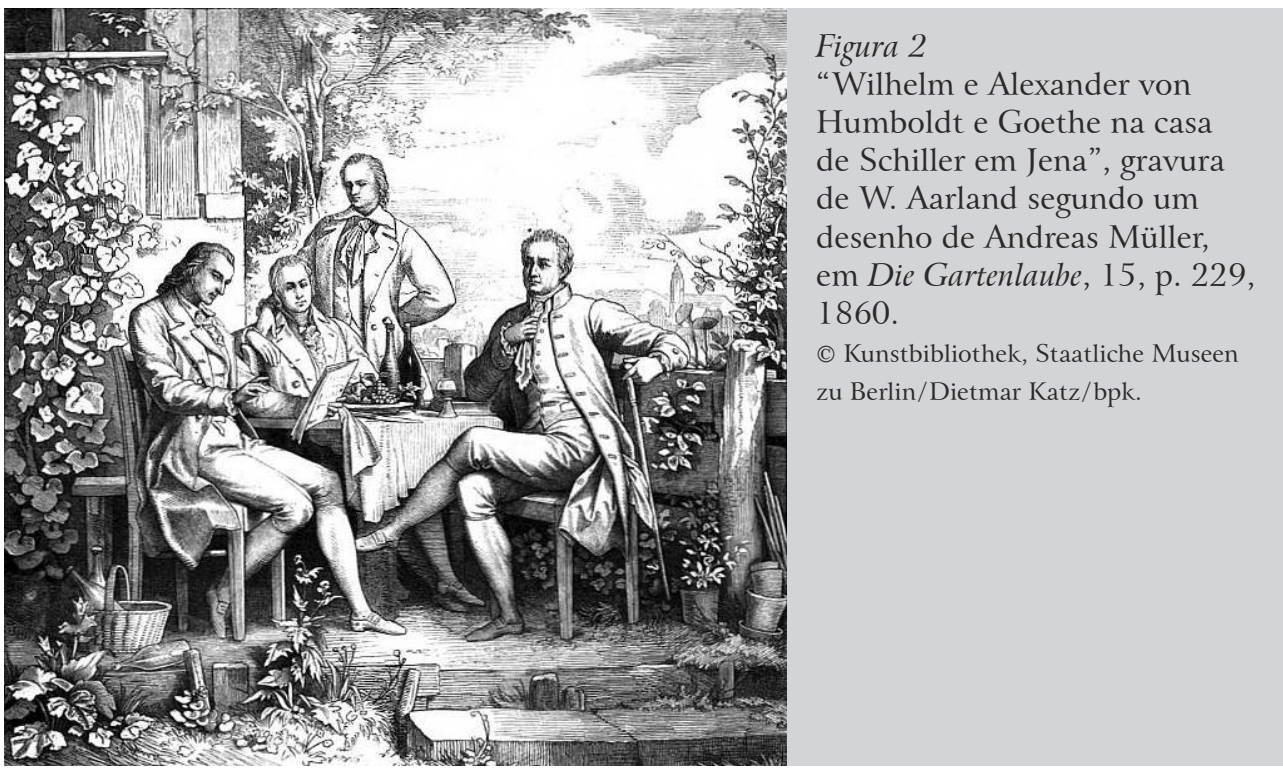

Viajante, botânico, geógrafo e humanista, Alexander von Humboldt sempre entendeu que o estudo rigoroso da natureza não podia excluir o papel da estética, quer no que respeita ao modo de a contemplar como totalidade, quer na arte de a escrever. Poeta, dramaturgo, romancista, Goethe, viu-se sempre também como cientista e colecionou tanto gessos da Antiguidade clássica grego-romana, como pedras; elaborou uma teoria das cores, interessando-se também por poesia persa, atento ao todo constituído pela natureza, pelos humanos, com as suas histórias, as suas experiências concretas. Em suma, ambos os homens partilharam não só interesses, leituras - a longevidade -, mas também a ideia de que a atenção ao concreto, ao empírico, não isentava o observador da importância a atribuir à correlação entre os fenómenos particulares e o mundo partilhado por todos os humanos, todos os seres orgânicos e não orgânicos sobre a Terra, ou seja, entre as partes e o todo.

Mas repare-se como o jovem Humboldt é representado. É o único de pé, sinal de respeito por parte da juventude. Note-se o gesto afetuoso, face ao irmão mais velho, futuro fundador da Universidade de Berlim, Wilhelm, o diplomata, linguista, filósofo, tradutor, mais realista, mais moderado nos entusiasmos do que o irmão, que, depois, vamos reencontrar com Aimé Bonpland, o primeiro dos grandes amigos e companheiros de viagens e de projetos científicos, na floresta virgem (figura 3).

Nesta imagem, Humboldt parece ter ocupado o lugar de Goethe, e é o amigo que surge em segundo plano. Note-se, ainda, os objetos, espalhados em torno. Dos instrumentos de medição da natureza aos animais, às plantas, estamos perante a imagem perfeita do explorador transformado em cientista, 


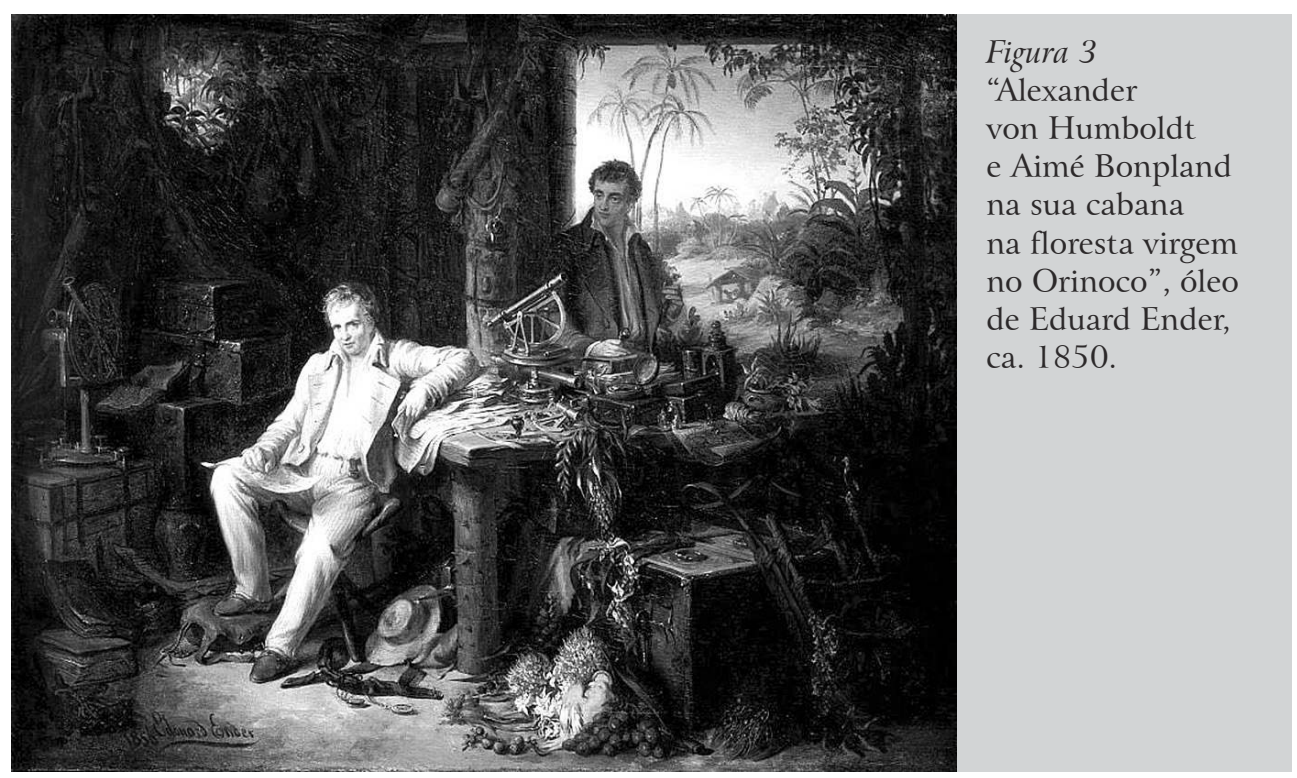

nova versão iluminista dos conquistadores do século XVI, novos Aguirres, agora menos em busca de Eldorados do que do trabalho industrioso, da ciência e do controlo através do olhar distanciado, recorrendo não à cruz e à espada, a cavalos e a cães, nem tão-pouco à varíola e às doenças venéreas, mas ao capital e à ciência, ao cronómetro e ao barómetro, à caneta e ao caderno de apontamentos, ao desenho e à cartografia, para dominar a natureza e os homens.

$\mathrm{Na}$ altura, não existiam nem máquinas fotográficas, nem vídeo - muito menos smartphones -, nem jipes nem aviões ou helicópteros, mas apenas mulas, lamas, canoas, liteiras, sendo estes novos conquistadores sempre transportados por guias indígenas, pormenores sem os quais as suas viagens, sabe-se hoje, não teriam sido possíveis, mesmo os percursos a pé e, sobretudo, a subida do Chimborazo, esse feito maior de ciência alpinista de que Humboldt e, mais tarde, Bolívar se vangloriaram (Pratt 1992: 180 ss.).

No Chimborazo, Humboldt exercerá o olhar totalizante próprio da consciência planetária, para assim reinventar a América (Pratt 1992: 124), mas ensaiará também a ideia de uma totalidade da natureza, que aqui (figura 4) surge como que condensada nas suas equivalências, não necessariamente hierarquias. Ou seja, Humboldt compara, traduz, tentando encontrar tanto diferenças como correspondências, atento à ideia de uma natureza, enquanto todo, que aprendera em jovem, com Georg Forster.

Mas gosto, ainda mais, de uma outra imagem de Humboldt na selva (figura 5). Mais naïf, primitivista, é também mais modernista, e Humboldt surge, aqui, de pé. São os mesmos objetos, as mesmas acumulações que surgem 


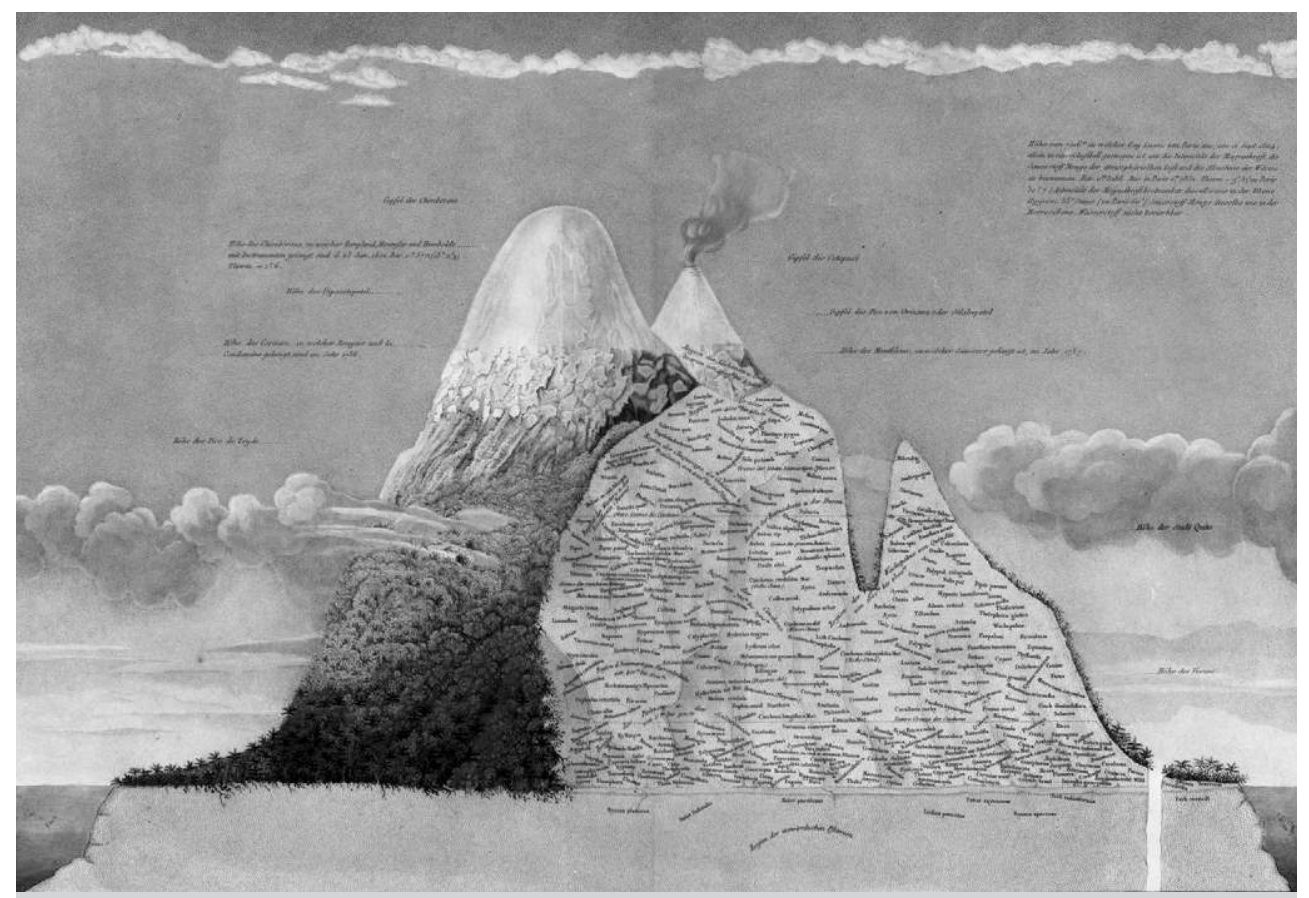

Figura 4 - "Geografia das plantas nas terras tropicais", de Alexander von Humboldt. (c) Klassik Stiftung Weimar/Olaf Mokansky/bpk.

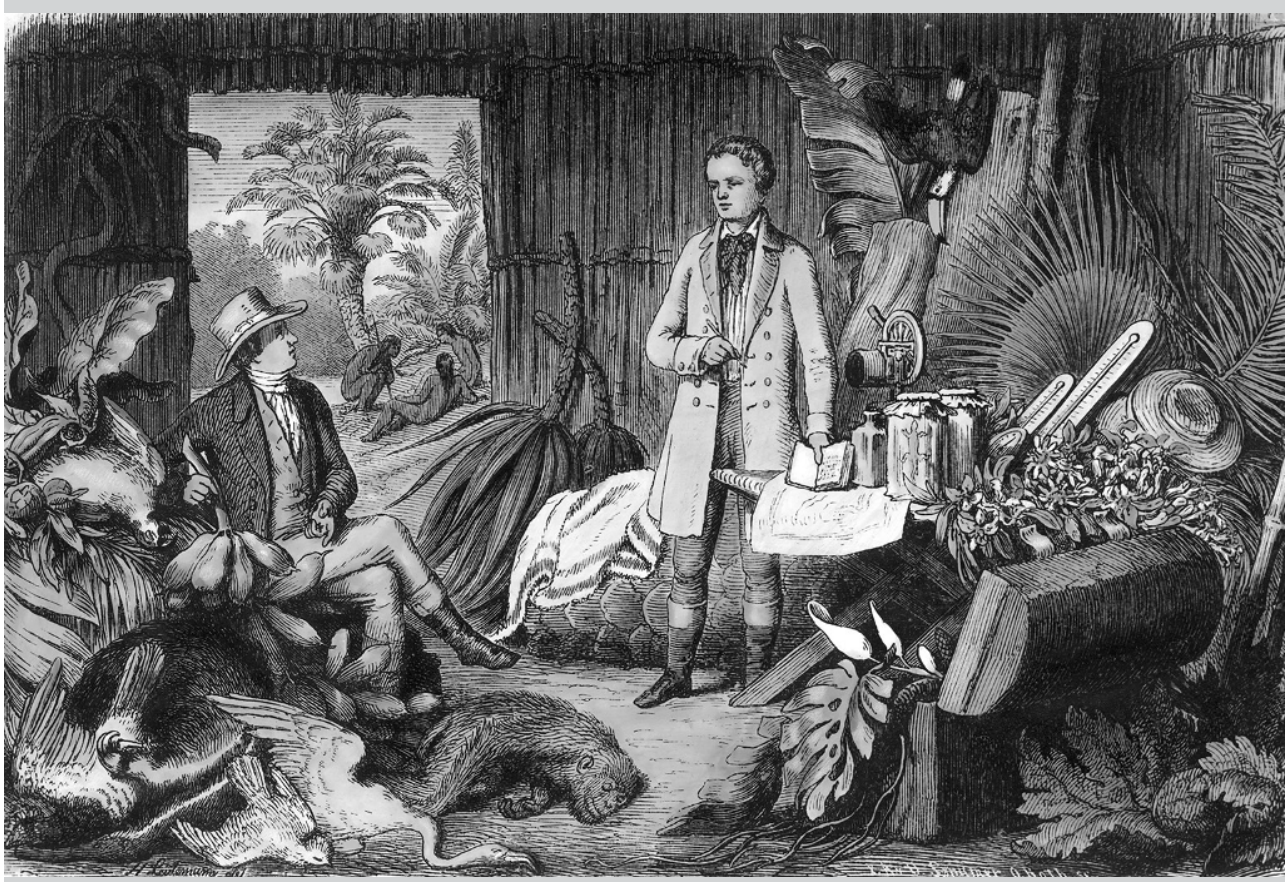

Figura 5 - Friedrich Georg Weitsch, "Alexander von Humboldt e Aimé Bonpland no sopé do Chimborazo. ๑ Stiftung Preussische Schlösser und Gärten Berlin-Brandenburg/Jörg P. Anders/bpk. 
na outra representação da cabana na selva (figura 3), mas aqui retratadas de modo mais cru, mais imediato. Mais uma vez, a natureza - dissecada, classificada, catalogada, empilhada - torna-se natureza morta, e os indígenas são mero pano de fundo, figurantes, nus e no estado natural, selvagem, contrastando com as casacas e a elegância dandy dos dois jovens que poderiam estar numa das margens do Sena.

Poder-se-ia concluir, como é habitual - se se estiver familiarizado com os estudos pós-coloniais ou, mais recentemente, com as abordagens descoloniais (por exemplo, Quijano 2000; Mignolo 2011) - que se trata de um exemplo da colonialidade, com a sua cumplicidade entre capitalismo e racismo, patente na coexistência da escravatura com a Constituição dos EUA ou com a Declaração dos Direitos do Homem e do Cidadão de 1789, com os seus falsos universais, colonialidade que a atual carta da Declaração Universal dos Direitos Humanos replicaria, inspirando, ainda hoje, guerras em nome de causas humanitárias ou da igualdade de género - veja-se o recente caso do burkini e dos valores da República Francesa e do Ocidente.

Mas há que não esquecer que, no tempo em que Humboldt viajava pelas Américas, o Haiti, então a colónia francesa de São Domingo, radicalizara, desde 1791, a Constituição Francesa e a Declaração dos Direitos do Homem e do Cidadão em que aquela se fundara, levando a que, em 1794, em plena época do Terror, se abolisse a escravatura, escravatura que Napoleão, o libertador dos povos da Europa, se apressaria, passados alguns anos, a reintroduzir. Ou seja, os subalternos - indígenas ou a diáspora forçada - sempre foram capazes de agenciamento, de subjetividade - por muitos revezes que tivessem sofrido, como o mostra a história da República do Haiti, fundada em $1804 .{ }^{4}$ E fizeram-no, também, apropriando-se do legado das Luzes, transformando-o, radicalizando-o, num programa efetivamente universal que também nunca viriam a concretizar completamente. C.L.R. James chamou-lhes jacobinos negros (James 1963).

Mas regressemos a Humboldt e ao seu busto de Goethe, em Berlim (figura 1), e detenhamo-nos, novamente, na relação entre geografia e literatura, entre o pequeno mundo de Jena e de Weimar, e as Américas de Humboldt e a Itália ou a Pérsia de Goethe, com as suas diferentes experiências, sublinhando o que esses dois homens possuíam em comum. Para Alexander von Humboldt e Goethe o mundo não se dividia nos compartimentos disciplinares e respetivas seitas, tais grupos étnicos, que se definem - como Fredrik Barth (1998 [1969]) há muito sublinhou - mais pelas fronteiras do que pelo que elas contêm. Pois,

4 Alude-se, neste contexto, ao célebre texto de Spivak "Can the subaltern speak?" (Spivak 1995), bem como a um ensaio menos conhecido, mas, em nosso entender, mais relevante, que escreveu em diálogo com o Grupo de Estudos do Subalterno (Spivak 1988). Note-se a importância destes não só para a disciplina da História, mas para os campos que aqui abordo. Sobre este tema, veja-se a introdução ao volume Deslocalizar a Europa (Sanches 2005). 
acrescentaria, o mundo é uma totalidade, desigual, é certo, mas desigualdade só inteligível se se cruzar saberes, se se introduzir outras perspetivas, outra largueza de vistas que permitam dar conta dessa complexidade, largueza de vistas que nem sempre, também é bom lembrar, encontramos entre académicos zelosos da sua especialidade.

O que pretendo destacar com estes exemplos, porventura anacrónicos, oriundos de lugares e tempos tão distintos - mas comparáveis - são menos os traços comuns e mais as vantagens do risco da pluridisciplinaridade, a capacidade de estarmos atentos ao que ao nosso lado se passa, geográfica e disciplinarmente, sobretudo a importância de uma visão multifacetada, que implica a visão do todo, o que, acrescente-se, não equivale necessariamente a um totalitarismo autoritário, mas pode, antes, ser sintoma de abertura ao mundo, para além do olhar preciso mas limitado do especialista que, no seu conforto, perde a visão da floresta de tanta atenção que presta à árvore. Será a conciliação entre os dois olhares possível?

Deixo esta questão, por ora, em suspenso, para abordar a inveja do terreno.

\section{A DESCOBERTA DA ANTROPOLOGIA:}

\section{ENTRE O CONCRETO (TERRENO) E A NARRATIVA (POLTRONA)}

Tive em tempos a fantasia de fazer um doutoramento em Antropologia. E porquê? Não se tratava apenas do fascínio pela diferença ou da nostalgia do exótico - contra os quais, note-se, nada tenho.

Já tinha aprendido, entretanto, que a antropologia não é sinónimo de estudo do "outro" ou, a sê-lo, esse chamado "outro" tem um sentido muito diferente daquele que lhe dão habitualmente os media, os discursos piedosos em torno da multiculturalidade, da interculturalidade, da "integração" dos "outros" na Europa.

Já tinha consciência, entretanto, de que não teria de ir viver para uma ilha do Pacífico ou para o meio da Amazónia. Não se tratava, assim ou só, de viajar, algo de que sempre gostei muito e ainda gosto. Aprendera, entretanto, que a antropologia não se detém apenas no distante, mas também lhe interessa o próximo. Tanto pode estudar um grupo longínquo, como uma tribo urbana vizinha, da FLUL ou do ISCTE, tanto elites locais como o Silicon Valley.

E fascinaram-me também os riscos - também os menos gloriosos - que o terreno implica, desde a capacidade de o antropólogo vencer, ou não, a timidez, à de interpretar os dados empíricos recolhidos, conferindo sentido a esses encontros contingentes, com os seus imponderáveis, as suas surpresas, os seus equívocos e os seus incómodos. Como interpretar, segundo que fio condutor? Como generalizar, abstrair, a partir desses dados, e quais os riscos que daí advêm? Dar importância ao funcionamento das instituições ou ao seu 
questionamento, ao grupo ou aos indivíduos, ao particular ou ao geral, ao que se mantém ou ao que muda? E serão estes dois planos separáveis? Perguntas, porventura, ingénuas, mas que talvez não faça mal lembrar, pois a ignorância é mãe de todo o espanto e também de todo o filosofar, como os gregos já nos ensinaram. São perguntas, também, que, na sua complexidade, me pareceram sempre fascinantes, na medida em que permitem uma articulação entre o concreto e o abstrato; o empírico, a experiência, e a teoria; o particular e o geral, o universal.

Contudo, a verdade é que, tenho de o confessar, o meu fascínio pela antropologia talvez advenha, também e sobretudo, da sua capacidade de contar histórias - pelo que peço absolvição -, pois a minha perspetiva é a de quem lê etnografias sentada na poltrona, sem nunca ter conhecido a experiência do terreno, esse rito iniciático necessário a todo e qualquer antropólogo: Franz Boas entre os inuit, vestindo a sua pele, Malinowski entre os trobriandeses (Malinowski 1984 [1922]), nunca abdicando da Englishness que muito lhe custara a adquirir, lendo Conrad ou ouvindo Wagner, escrevendo cartas desesperadas à noiva, entre tiradas racistas que muito escândalo viriam a causar (Malinowski 1989), Lévi-Strauss e a sua estranheza tanto perante os nambikwara como perante as elites paulistas (Lévi-Strauss 1955), Michel Leiris, na viagem Dakar-Djibuti (Leiris 1996 [1934]), observando, perturbado, os ritos de possessão na Etiópia e o saque a que as comunidades visitadas eram sujeitas - experiências contraditórias, dando a ver formações, expectativas diferentes. ${ }^{5}$

Mas estas são descobertas posteriores no meu percurso. A verdade é que o encontro e o meu interesse pela antropologia decorrem de um autor, amigo e mentor de Alexander von Humboldt, a quem dediquei vários anos da minha vida, precisamente quando fazia o meu doutoramento.

Quem era esse autor?

Trata-se de Georg Forster (1754-1794), nascido no que hoje é Polónia, então território dependente do Reino da Prússia, filho de um pastor evangélico, Johann Reinhold Forster, este último mais interessado em Ciências Naturais, Botânica e Ciências do Homem ou na História da Humanidade - como eram chamadas as disciplinas que viriam a dar lugar à Antropologia -, do que em religião (figura 6).

O jovem Georg seguirá o pai numa viagem até à Rússia, sob a égide da colonização alemã com que a grande Catarina pretendia civilizar os povos "bárbaros" eslavos, indo depois para Londres, onde, também com o pai, teria ocasião de participar na segunda circum-navegação de James Cook, entre 1772 e 1775 (figura 7), três anos que seriam a sua universidade, segundo Friedrich Schlegel (Schlegel 1985 [1797]). A viagem levá-lo-ia a lugares tão distantes e distintos 


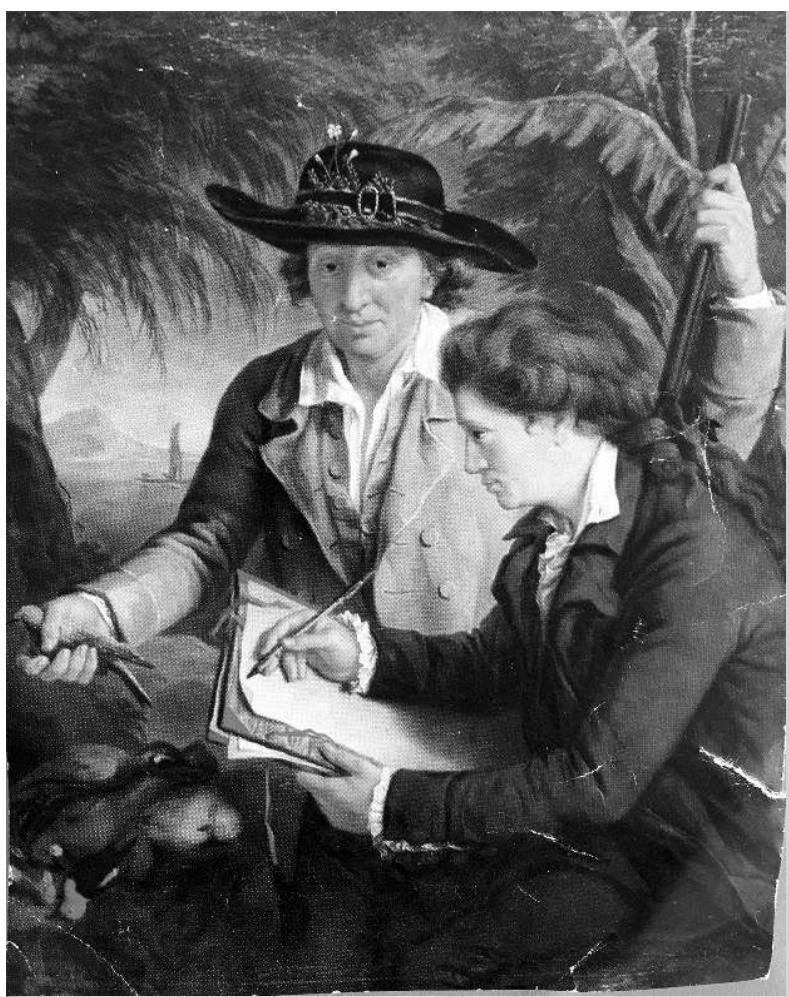

Figura 6

Johann Reinhold Forster

e Georg Forster em Taiti, óleo de John Francis Rigaud, 1780.

Fonte: fotografia da autora, segundo uma imagem oferecida por Gerhard

Steiner, editor da edição crítica de Georg Forster da Academia das Ciências de Berlim, RDA.

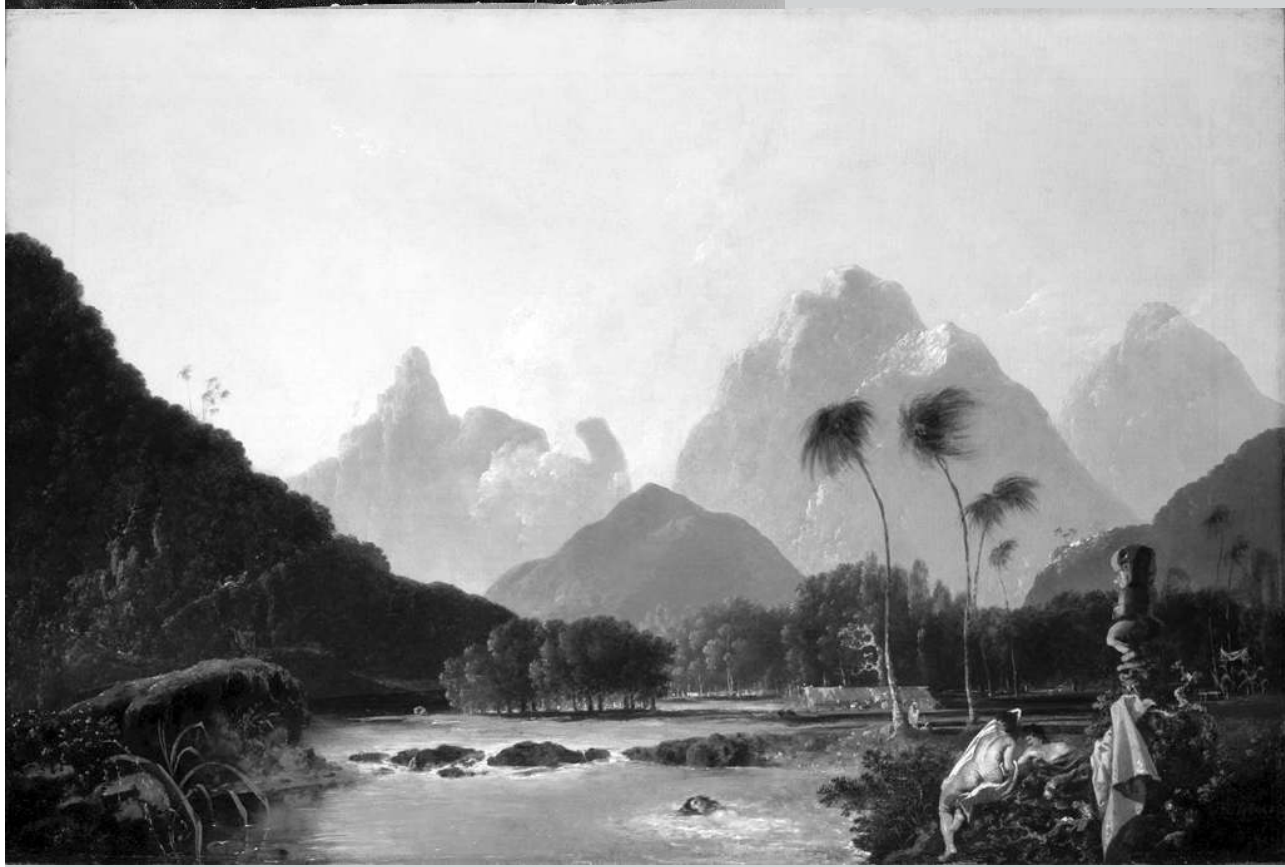

Figura 7 - William Hodges, "Vista da Baía de Maitavie em Taiti”, 1776. (c) National Maritime Museum, Greenwich, London, Ministry of Defence Art Collection. 
como a mítica Taiti (figura 7), ${ }^{6}$ as Ilhas Marquesas, a Nova Zelândia, a Nova Caledónia, a Ilha de Páscoa, mas também à Cidade do Cabo, a Cabo Verde, aos Açores, à Madeira, à Antártida, à Patagónia, projeto que trai não só a curiosidade científica mais ou menos desinteressada como a vontade de poder e de controle do mundo por parte dos imperialismos europeus. A expedição foi marcada por sucessos importantes, mas pouco espetaculares; entre outros, o das vantagens da higiene a bordo e da alimentação equilibrada, evitando-se assim o escorbuto fatal - bem como a descoberta de que não havia mais continentes a descobrir.

Regressado à Europa, depois de ter escrito a sua narrativa da viagem à volta do mundo (Forster 1986 [1777]), Forster dedicar-se-ia a experiências tão empiricamente fundadas quanto esotéricas na cidade de Kassel com o amigo anatomista Thomas Soemmerring, antes de se instalar em Mainz como bibliotecário do que então era um arcebispado católico. Em 1789, seguira já atentamente os acontecimentos em França, visitando, pouco depois, com o jovem Alexander von Humboldt e o seu irmão Wilhelm, os Países Baixos, a Renânia e também Paris, para mais tarde aderir à República Francesa, quando as tropas girondinas ocuparam a cidade. Membro da Convenção republicana local, Georg Forster fará parte da delegação que se deslocará a Paris para propor a integração do arcebispado na jovem República Francesa. Mas será surpreendido, na capital da revolução, pela captura da cidade de Mainz, entretanto cercada por tropas prussianas e austríacas, cerco que Goethe presenciou, pelo que Forster se verá impedido de regressar, não à pátria - pois Forster era como Humboldt um errante -, mas de rever a família - e a sua biblioteca e textos -, morrendo em Paris, em plena época do Terror, cuja violência tentou interpretar e justificar. Morreu, diz-se, com um mapa da Índia ao lado, lugar onde sonhara ir. Traduzira do inglês o famoso Śakuntalā, que tão importante seria para os orientalistas alemães, entre eles o irmão de Alexander, Wilhelm von Humboldt. Walter Benjamim incluiu, sob o pseudónimo de Detlev Holz, uma das cartas de Georg Forster à mulher na coletânea Deutsche Menschen (Benjamin 1991 [1936]: 160161), prestando, numa breve introdução, homenagem a esse revolucionário cosmopolita e apátrida, condição com a qual se identificava e que atingiu o seu momento mais trágico com a sua morte em Portbou, na fronteira entre a França e a Espanha, a caminho dos EUA, em 1940.

Forster foi, como o seu amigo Alexander von Humboldt, um polímato, geógrafo, protoantropólogo, como, de resto, Johannes Fabian o reconhece no seu

6 Esta imagem de William Hodges, retrabalhada a óleo a partir de desenhos e esboços feitos localmente, constitui não só uma tradução, adaptação, considerando o gosto do público europeu de então, como revela, a par de outros quadros famosos da segunda circum-navegação de James Cook, o modo como a iconografia neoclássica influenciou estas representações, mas também a descoberta de uma nova luminosidade e estética local foi fundamental para o movimento romântico nas artes visuais, nomeadamente em William Turner (Smith 1985), mais um exemplo de transculturação (Pratt 1992). 
livro Time and the Other (1983: 86), escritor sublime em língua alemã, inglesa, dominando também o francês, o italiano, compreendendo o português. Interessou-se também por arte, literatura, estética e pelos direitos humanos, combatendo todas as formas de racialismo científico que pretendiam justificar a escravização de alguns humanos. Polemizou com Kant sobre as raças humanas, mas, sobretudo, denunciou as teorias e as metodologias racialistas e racistas, fundadas numa ciência cada vez mais positivista e sistemática, que pretendiam criar uma relação de causalidade entre corpo e mente, raça e cultura, com as suas hierarquias habituais. Tais metodologias tornavam-se, já então, cada vez mais preponderantes entre os representantes da antropologia física, não tanto o célebre Blumenbach, como Christoph Meiners, verdadeiro precursor do eugenismo do século XX, que muito influenciou a antropologia física francesa, ${ }^{7}$ tão decisiva, por sua vez, para a que entre nós se praticou, sobretudo na Universidade do Porto, graças ao papel sombrio de Mendes Correia, antes de a influência de Boas se fazer sentir por via de Jorge Dias.

Mas, pesem embora todas estas posições que nos impedem de ver nas Luzes um universo monolítico, como muitas vezes sucede nas abordagens pós-coloniais e descoloniais, Forster foi, necessariamente, como Alexander von Humboldt - permitam-me este hegelianismo -, um filho do seu tempo, com o seu eurocentrismo e a sua filosofia da história, versão secularizada de uma teodiceia agora projetada num futuro permanentemente adiado (Koselleck 1989). Contudo, a sua viagem à volta do mundo e a respetiva narrativa, dependente como esta tinha de ser do universo evolucionista do seu tempo, também lhe permitiram reconhecer que a variedade do género humano era, por vezes, inexplicável ou não redutível a padrões de explicação europeia; que a experiência servia não para se proclamar um conhecimento pretensamente objetivo, positivista, do género humano, mas antes para questionar evidências e, sobretudo, como forma de abertura e curiosidade pelo mundo.

Foram todas estas questões suscitadas pela leitura de uma obra multifacetada que me levaram, então, a ler muitos antropólogos, a descobrir, primeiro, Lévi-Strauss, depois, ainda com mais entusiasmo, Michel Leiris (1996 [1934], 2011 [1950]), antropólogo-escritor por excelência, antes de reconhecer as afinidades entre a antropologia cultural norte-americana e as premissas em que Forster se movera, fruto das viagens da teoria (Said 2005 [2000]) e de Franz Boas (Stocking Jr. 1996), cristalizadas na ideia de personalidade e cultura, reproduzindo a ideia romântica alemã da psicologia dos povos, o espírito do povo de Herder ou o caráter do povo de Wilhelm von Humboldt, com as suas potencialidades e problemas.

7 Estes textos foram traduzidos e apresentados na antologia que reuniu estes debates, entre outros, com o título A Invenção do "Homem" (Sanches e Serrão 2002). 
E houve, depois, a descoberta de Orientalismo de Edward Said (1995 [1978]), um livro que mudou a forma como vira o mundo; a seguir, a de Writing Culture (Clifford e Marcus 1986), da chamada antropologia pós-moderna, com a sua atenção, menos ao narcisismo do antropólogo, do que aos processos de constituição da verdade sobre o "outro", com a sua ênfase no campo das relações de poder, nos processos formais, literários, com as respetivas e necessárias implicações teóricas, filosóficas, políticas. Seguiu-se-lhe o aprofundamento dos estudos pós-coloniais, abordagem inicialmente derivada dos estudos literários, usando as suas ferramentas hermenêuticas ou a semiótica para alargar os seus objetos de estudo e práticas disciplinares, bem como os textos aos contextos em que haviam sido produzidos, como que retomando, em sentido inverso, o interesse das ciências sociais em geral - não só da antropologia, mas também da história -, pelos procedimentos formais que haviam aprendido com os estudos literários.

Mas o que a antropologia acrescentava era sempre a importância da experiência no terreno, como Forster já o soubera reconhecer, ao mesmo tempo que também reconheceu que a observação nunca pode ser objetiva, mas sempre parcial, determinada pelo ponto de vista do observador, as suas "lentes", como escreveu ainda jovem (Forster 1986 [1777]). Isto não o impediu, como bom iluminista, de entender que esse perspetivismo tinha de desembocar num ensimesmamento narcisista, na celebração da diferença irredutível, se abdicasse do diálogo com outras versões, todas elas parciais, mas que, a serem cotejadas, aferidas, discutidas, permitiriam constituir um processo de aproximação à verdade (Sanches 1994), no reconhecimento de que existe, apesar da diversidade humana, uma humanidade comum e que, a haver universais, acrescentaria, eles nunca podem ser impostos, mas definidos em conjunto.

\section{DA LITERATURA (DE VIAGENS) À ANTROPOLOGIA}

Perguntei muitas vezes a mim mesma porque escolhi Georg Forster para tema de doutoramento. Antropóloga frustrada? Não sei, nem vou entrar em especulações de ordem psicologizante, mas tão-só recordar que foi decisivo o desejo de viajar, do risco, de fugir ao quotidiano, que nos dá segurança, que nos ancora, mas que também nos oprime, entedia. Ainda me lembro de começar a ler Viagem à Volta do Mundo, com um atlas ao lado, para localizar as diversas ilhas no Pacífico imenso, muito azul, nessa altura, de papel - e sem Google Maps.

Mas, antes de todas estas descobertas teóricas e académicas, tinha havido outras experiências. Não de viagens a sítios exóticos, onde nunca fui verdadeiramente, nem me senti nunca particularmente atraída a ir - preferi sempre a poltrona -, mas a da leitura de livros de aventuras, porventura colonialistas, preferindo sempre a biblioteca dos rapazes - Júlio Verne, Emilio Salgari, Robert Louis Stevenson, Herman Melville, sempre em versão infantil, para não falar na Odisseia contada às crianças. Creio que tanto o gosto pela viagem 
como pela literatura de viagens foram decisivos para a escolha do meu tema de doutoramento. O que, mais tarde, me levou à descoberta do prazer da leitura, do prazer do texto, de várias etnografias, de Os Argonautas do Pacífico Ocidental (Malinowski 1984 [1922]) a Afrique fantôme (Leiris 1996 [1934]) ou Never in Anger (Briggs 1970) - para citar uma antropóloga, entre as muitas existentes -, além de outros textos de viagem, que fui descobrindo depois, textos de maior ou menor qualidade, mas sempre objetos de estudo interessantes, para me deparar, mais recentemente, com viagens tão europeias, mas tão capazes de questionamento próprio, como as de W. G. Sebald.

Portanto, gosto pela aventura, elogio do exótico, distanciamento do familiar, digo-o contra todos os discursos e dúvidas a que a descolonialidade nos obriga hoje, pois é nesse fascínio que encontro ainda muito do entusiasmo e problemas da antropologia. Mas também de confronto, de questionamento de mim mesma, de seguranças e evidências disciplinares.

É certo que a literatura de viagens e de descobertas, de que as melhores etnografias são herdeiras, é uma literatura centrada num eu, predominantemente masculino, que "descobre", unilateralmente, um mundo povoado de "selvagens" e de paisagens exóticas, de corações das trevas - os humanos sempre representados como "outros", sempre destituídos de voz, seres passivos à espera que a palavra do viajante - do descobridor, do conquistador, do missionário, do cientista, do colonizador - lhes dê forma, sentido, como alma a converter, objeto a estudar, selvagem ou colonizado a civilizar, ou seja, sempre a ser salvo de si mesmo, sempre um "outro" passivo, nunca subjetividade plena. Ou meio de o descobridor, conquistador, cientista ou escritor, em suma, de o viajante se redimir, regressado à tenda, a casa ou à sua universidade de origem. À sua secretaria. À sua poltrona.

Mas, apesar de todos estes problemas, não posso deixar de reconhecer que a aventura, a procura do desconhecido, do risco, ainda continuam a seduzir-me na literatura de viagens clássica e em todos os seus sucedâneos, narrativas em que se misturam, se fundem ou entram em tensão o desejo de fuga e de controle, o desconhecido e o conhecido, a incerteza e as seguranças.

E, sobretudo, há o desejo de narrar a aventura, com as suas contradições, vitórias e derrotas, narração que, em retrospetiva, legitima os tormentos, as aflições, as noites mal passadas, as doenças, os desconfortos, até os mais comezinhos, como os mosquitos que, parece, tanto fizeram Humboldt sofrer.

Ora, é tudo isso que como que fica redimido na boa literatura de viagens, em que incluo tanto as grandes reportagens - Pedro Rosa Mendes seria um exemplo, Paul Theroux nunca -, como grandes romances - Joseph Conrad seria o exemplo mais óbvio, Ruy Duarte de Carvalho não menos -, ou mesmo as epopeias clássicas, desde a Odisseia à epopeia de Sundiata. E, claro, as melhores etnografias, Malinowski (1984 [1922]) ou Evans-Pritchard (1965 [1940]) - para citar alguns dos mais conhecidos -, que não só oferecem o prazer do 
texto, mas são, parece-me, também o resultado do prazer da narração, narração só completada no regresso a casa, no conforto da poltrona, dando sentido e finalidade ao caos das anteriores experiências, tarefa agora solitária, mas a pensar no leitor, que irá descobrir mundos distintos do seu, ao mesmo tempo que pode rever-se neles.

Com efeito, não será o desejo de viajar e do terreno sempre um desejo de os narrar? Narrar para aqueles que sabem ouvir - sabemos bem demais até que ponto é difícil encontrar quem saiba escutar os nossos relatos de viagem, a maior parte dos amigos e família mais interessados, quando regressamos, em contar as suas atribulações de gente imóvel do que em ouvir as nossas aventuras e peripécias em espaços mais ou menos longínquos -, para os amigos, os curiosos, os colegas e pares, mas sobretudo para os leitores anónimos, porventura os genuinamente interessados. Lembre-se a obsessão de Humboldt em narrar a sua viagem pelas Américas, a que dedicou a maior parte da sua longa vida, escondendo sempre a sua subjetividade, que entendia secundária, nos milhares de páginas da sua vastíssima obra. ${ }^{8}$

E a narrativa das observações no terreno não tem de equivaler sempre a um resultado inovador - para usar do jargão neoliberal -, nem à vitória de se ter avançado no conhecimento - traduzido para aquele jargão -, de se ter obtido muitos outputs ou indicadores. Não serão as grandes narrativas de fracassos, como, por exemplo, Tristes Trópicos (Lévi-Strauss 1955), "Afrique fantôme" (Leiris 1996 [1934]), Never in Anger (Briggs 1970) e mesmo de The Nuer (Evans-Pritchard 1965 [1940]), aquelas de onde podemos extrair ainda maior prazer, não tanto pela justeza das suas observações, como pela forma como são narradas, vivendo esses textos tanto da sua verosimilhança como das suas verdades, finalmente, sempre parciais (Clifford 1986)? Esse prazer não tem de excluir a reflexão política sobre o sentido da disciplina e das suas consequências. Bem pelo contrário.

8 "Há pormenores da vida comum que poderá ser útil registar num itinerário, pois servem para orientar o comportamento daqueles que percorrem as mesmas paragens depois de nós. Deles conservei um pequeno número; mas suprimi a maior parte dos incidentes pessoais que não oferecem um verdadeiro interesse para a situação e aos quais só a perfeição do estilo pode conferir harmonia" ["Il est des détails de la vie commune qu'il peut être utile de consigner dans un itinéraire, parce qu'ils servent à régler la conduite de ceux qui parcourent les mêmes contrées après nous. J'en ai conservé un petit nombre: mais j'ai supprimé la plupart de ces incidens personnels qui n'offrent pas un véritable intérêt de situation, et sur lesquels la perfection du style peut seule répandre de l'agrément"] (Humboldt 1814: 32). Humboldt chega a mencionar a "extrema repugnância em escrever o relato da sua viagem" ["extrême répugnance à écrire la relation de mon voyage"] (Humboldt 1814: 29). Dada a inexistência de uma tradução generalizada das obras de Humboldt, optou-se por consultar e traduzir o original em francês. Existe, contudo, uma tradução fidedigna em língua inglesa (Humboldt 1995 [1814-1825]) que omite - por vezes excessivamente - as longas digressões de Humboldt, mas que também desmente a fama de empolamento estilístico que se tornou regra censurar no viajante e que o original francês, como o tradutor sublinha, e posso confirmar, não possui (Wilson 1995: lvi-lx). 
Em suma, todas as questões que enunciei - e são efetivamente muitas - mostram o pouco que sei, mas o muito que aprendi com a antropologia e porque é que ela é importante e faz sentido, pesem embora a sua história colonial, a sua cumplicidade com o colonialismo e o imperialismo, ou, versões mais recentes, o seu contributo para o estudo das culturas de um modo muito complexo. Daí, porventura, os equívocos e a sua dificuldade em fazer passar a mensagem (Herzfeld 2001) - mesmo dentro da disciplina, sublinhando-se ainda a noção de cultura associada a padrões claros e bem delimitados, ignorando o modo como esta é muito mais definida através da fronteira e na fronteira (Rosaldo 1993 [1989]).

Mas se algo aprendi também com a antropologia foi - porque, digna herdeira da melhor literatura de viagens, mo conseguiu transmitir - a sua curiosidade, a sua vontade de sair do óbvio e familiar, o seu desejo do exótico, digamo-lo sem peias, a sua abertura à aventura e ao risco, por muito colonial que fosse. Também o risco de sermos capazes de nos questionarmos a nós mesmos.

\section{LER ENTRE CULTURAS}

E, assim, volto à literatura de viagens como protoantropologia com todas as suas potencialidades e problemas, para abordar uma questão sempre latente e que gostaria de desenvolver antes de concluir - o tema da tradução.

Esse desejo do exótico e a literatura de viagens dele resultante não é ele, ou não pode também ser, uma tentativa de traduzir o que se viu, percecionou subjetivamente para, depois, ser retrabalhado, reinterpretado pelo leitor? E para o autor se expor, se questionar a si mesmo? E o que se passa no regresso, no momento em que, na poltrona, compilamos as nossas notas, as relemos, para as estruturar num todo, não digo necessariamente coerente, mas minimamente inteligível? Escrever cultura é sempre traduzir culturas, com as suas fidelidades e traições, os seus equívocos, que podem ser produtivos, se houver consciência dos nossos limites.

Tenho alguma prática de tradução linguística - a teoria nunca me interessou-, essa tarefa, em que, ao contrário da angústia da página em branco, temos a segurança de um texto prévio que recriamos, reinventamos. O que pretendo sempre fazer é respeitar o original, mas de modo a que soe bem na língua para a qual traduzo, sempre o português, ao mesmo tempo que tento assegurar que não se perca a estraneidade do texto que lhe subjaz. Mas, para se compreender e conservar essa estraneidade, carece-se de um conhecimento profundo não só da língua, da cultura do texto de que se traduz, mas também daquela para a qual se verte o original, no reconhecimento daquilo que existe de comum e de diferente entre ambos os universos; e, para se ser fiel ao original, há que o trair e mesmo reconhecer que há sempre uma parte que fica perdida na tradução, desorientação fundamental que impede que as peças desse puzzle encaixem na perfeição. Mas sem que a inteligibilidade se perca. 
Joga-se aqui uma questão entre o particular e o geral ou o universal que os antropólogos certamente conhecem, questão que remete para o problema complexo de como se narra, traduz, a diferença, o que implica a articulação entre as partes e o todo, recusando seja a ver-se tão-só a árvore quanto a floresta como um coletivo que não dá lugar à individualidade de que esta também depende, para retomar uma questão atrás enunciada.

Contudo, a diferença não tem de ser sempre a do "outro" exterior a nós, mas a do reconhecimento de que somos, também nós, diferentes - de preferência, sem hierarquizações paternalistas nem vontade de poder, seja quando descrevemos o nosso quotidiano e, nele, reencontramos, na melhor tradição surrealista, o exótico, seja quando, antropólogos indígenas, tentamos não sucumbir a tentações essencialistas, por muito boas que as nossas intenções políticas possam ser. Reconhecendo, sempre, que a diferença é algo de produzido (Gupta e Ferguson 1992), nunca de dado, atentos aos mecanismos de poder, em que, quer a política, quer a poética dos processos de representação (Hall 1997) - fatalmente associados à tradução - são igualmente importantes.

Ou seja, se a minha inveja do antropólogo tanto se prende com a nostalgia e a narração do exótico - fantasias de poltrona -, como com o reconhecimento da importância da experiência do terreno, também é verdade que, em ambos os casos, se está sempre a tentar comunicar, a traduzir diferenças, ou seja, a comparar dois universos que nunca são - cada vez menos estão - completamente separados. O que não significa que a passagem de um para o outro seja fácil ou óbvia, o que torna a tradução entre universos culturais e disciplinares tanto mais relevante.

Em suma, o que fazemos na poltrona pode, afinal, não ser tão distinto daquilo que os antropólogos fazem, mesmo, no terreno. Há muito mais afinidades do que imaginamos entre letrados imóveis e etnógrafos errantes, face ao ato de tradução que também é, sempre, um ato de comparação.

E voltando à primeira imagem: mesmo que os livros estejam muito arrumados nas estantes e os documentos, espécimenes e artefactos classificados, há sempre os arquivos e mapas que permanecem abertos, espalhados no chão, fora da estante, assuntos por resolver que adiamos ou a que voltamos recorrentemente, por muito saber ou experiência acumulada que tenhamos. É isso que também lemos na imagem do velho Humboldt. E é por isso que aqui não vos trago certezas do meu aposento, mas antes um conjunto de reflexões a serem prosseguidas por quem conseguiu ler este texto quase até ao fim.

\section{CODA}

Permitam-me só uma nota final. Antes de começar a esboçar o texto que aqui apresento, terminei a tradução de um outro texto, o diário que Werner Herzog 
escreveu durante a rodagem de Fitzcarraldo (Herzog 2009 [2004]). Filme maldito para antropólogos ou indigenistas new age, uma leitura mais demorada, seja do filme, seja dos contextos em que foi produzido, permite que ele não seja reduzido a um horror picture show, como, na altura, a imprensa alemã - não só a tabloide - e ativistas europeus com veleidades terceiro-mundistas (Sabourin 1980) o pretenderam. ${ }^{9}$

A leitura atenta do livro, significativamente intitulado Conquista do Inútil (Herzog 2017 [2004]) - e nada há como uma tradução para se ler atentamente um texto, descobrindo não só as nossas leituras equivocadas, mas também os próprios equívocos do autor -, permite reconhecer que o que está em causa não é finalmente a conquista - embora essa vertente também esteja presente -, mas antes o reconhecimento da inutilidade desse sonho masculino, "ocidental", que pretende dominar homens e natureza, para, finalmente, ficarmos a sós connosco mesmos, com os nossos limites, como quando começamos a escrever, perante o horror da página em branco.

E Herzog escreveu, permanente, obsessivamente, como muitos antropólogos, o seu diário. Como Malinowski, com Joseph Conrad, lendo Bruce Chatwin, Joseph Roth, Tito Lívio, ouvindo Bach, Schütz, Vivaldi; escreveu numa letra microscópica, para que ninguém, na altura, pudesse decifrar as suas notas; escreveu contra a derrota iminente, contra os conflitos com humanos e com a natureza; escreveu contra os conflitos consigo mesmo, que, como Humboldt, quis silenciados, mas redimidos na sua obra ${ }^{10}$ conflitos que via replicados numa selva, não como totalidade harmoniosa; antes ameaçadora, inclemente, mas não menos sedutora.

Finalmente, perceberia a inutilidade do seu projeto megalómano e destruidor. E também - depois de ter lamentado, com o habitual rasgo de nostalgia imperialista (Rosaldo 1993 [1989]), a morte de culturas e línguas, bem como os óculos Ray-Ban e as $t$-shirts com "Disco Fever" dos ativistas indígenas, adereços que estes sabiam substituir estrategicamente por penas, arco e

9 Da imprensa alemã, veja-se os textos de 1979 "Ein Gringo im Urwald" em Der Spiegel, n. ${ }^{\circ}$ 37, pp. 246-249, disponível em < http://www.spiegel.de/spiegel/print/d-39909494.html > (consultado em 9 de janeiro de 2017), ou "Die Herzog-Horror-Picture-Show", assinado por Manfred von Conta em Stern, 29 de novembro, pp. 100-113.

10 Seria de salientar uma coincidência interessante entre Humboldt e Herzog - cujo papel o último representou no filme de Edgar Reisz Die andere Heimat, Chronik einer Sensucht (2013), filme em que a América constitui o antídoto à Heimat - no desejo de que a obra se sobreponha ao indivíduo por detrás dela. Alexander von Humboldt, a quem tantas biografias têm sido dedicadas (Rupke 2008), escreveu a Mary Somerville, geógrafa escocesa, que "A vida de um letrado são as suas obras" (apud Leitner 1995: 23). Por sua vez, Herzog foi objeto de dois documentários com o título Aquilo Que Sou São os Meus Filmes (Was ich bin sind meine Filme, 1978 e 2010). De notar ainda o modo como o realizador tem construído uma persona através de múltiplas entrevistas, assim garantindo o controlo sobre a sua biografia e obra, pesem embora os inúmeros avatares que a Internet tornou, entretanto, possíveis. 
flecha, como também anotou, irritado e perplexo (Herzog 2009 [2004]: 74) reconhecer a legitimidade dos seus direitos aos seus territórios contra interesses de companhias petrolíferas e de estados-nação. Indígenas que nunca tinham visto o mar, mas que o queriam ver, provar, para confirmar que era efetivamente salgado, levando amostras dele, como prova empírica, para casa (Herzog 2009 [2004]: 312).

Exatamente como Humboldt. Mas com menos poder. Muito menos. E claro que conhecemos apenas uma das versões, subalternizadas que as vozes indígenas foram e ainda são. Mas este seria um outro tema.

Em suma, deixo-vos com meras impressões, narradas como sei e posso, não uma teoria, mas algumas certezas: a certeza da importância da curiosidade pelo que não nos é familiar - com as suas potencialidades e os seus equívocos, os seus riscos -, bem como das narrativas que ela gera; a certeza da vantagem de olharmos além do nosso jardim, arriscando a nossa segurança, através do terreno concreto ou da capacidade de testarmos os limites, as fronteiras, entre culturas, saberes, disciplinas.

Permitam-me só que conclua com um conselho, ditado pelo conforto - por vezes, penoso, porque solitário, mas tanto mais criativo, da poltrona e também por uma vida, cheia de contradições, que, felizmente, já vai algo longa: não receiem o risco; não abandonem os vossos sonhos, mesmo que antecipem possíveis derrotas, pois elas nunca são inúteis.

Sobretudo, não receiem este começo. Que não será absoluto; não será inaugural, mas que trará, certamente, muitas coisas novas. E boas.

\section{BIBLIOGRAFIA}

BARTH, Fredrik, 1998 [1969], Ethnic Groups and Boundaries: The Social Organization of Culture Difference, Long Grove, IL, Waveland Press.

BENJAMIN, Walter, 1991 [1936], "Deutsche Menschen: Eine Folge von Briefen. Auswahl und Einleitung von Detlev Holz", em Rolf Tiedemann e Hermann Schweppenhäuser (orgs.), Gesammelte Schriften, vol. IV. Suhrkamp, Frankfurt am Main, 149-233.

BRIGGS, Jean, 1970, Never in Anger: Portrait of an Eskimo Family. Cambridge, MA, Harvard University Press.

CLIFFORD, James, 1986, "Introduction: partial truths", em James Clifford e George E. Marcus (orgs.), Writing Culture: The Poetics and Politics of Ethnography. Berkeley, CA, University of California Press, 1-26.

CLIFFORD, James, 1988, The Predicament of Culture: Twentieth-Century Ethnography, Literature, and Art. Cambridge, MA, e Londres, Harvard University Press. 
CLIFFORD, James, e George E. MARCUS (orgs.), 1986, Writing Culture: The Poetics and Politics of Ethnography. Berkeley, CA, University of California Press.

EVANS-PRITCHARD, Edward E., 1965 [1940], The Nuer: A Description of the Modes of Livelihood and Political Institutions of a Nilotic People. Oxford, Oxford University Press.

FABIAN, Johannes, 1983, Time and the Other: How Anthropology Makes Its Object. Nova Iorque, Columbia University Press.

FORSTER, Georg, 1986 [1777], A Voyage Round the World. Berlim, Akademie Verlag (org. R.L. Kahn).

FOSTER, Hal, 2005 [1996], “O artista como etnógrafo", em Manuela Ribeiro Sanches (org.), Deslocalizar a "Europa”: Antropologia, Arte, Literatura e História na Pós-Colonialidade. Lisboa, Cotovia, 259-296 (trad. Manuela Ribeiro Sanches).

GEERTZ, Clifford, 1973, The Interpretation of Cultures: Selected Essays. Nova Iorque, Basic Books. GEERTZ, Clifford, 1988, Works and Lives: The Anthropologist as Author. Oxford, Polity Press.

GUPTA, Akhil, e James FERGUSON, 1992, “Beyond 'culture': space, identity, and the politics of difference", Cultural Anthropology, 7: 6-23.

HALL, Stuart (org.), 1997, Representation: Cultural Representations and Signifying Practices. Londres, Thousand Oaks e Nova Deli, Sage.

HERZFELD, Michael, 2001, Anthropology: Theoretical Practice in Culture and Society. Oxford, Blackwell/Paris, UNESCO.

HERzOG, Werner, 2017 [2004], Conquista do Inútil. Lisboa, Tinta da China (trad. Manuela Ribeiro Sanches).

HUMBOLDT, Alexander von, 1814, Voyage aux régions équinoxiales du Nouveau Continent: fait en 1799, 1800, 1801, 1803 et 1804, vol. 1. Paris, F. Schoell.

HUMBOLDT, Alexander von, 1845-1862, Kosmos: Entwurf einer physischen Weltbeschreibung, 5 vols. Stuttgart e Tübingen, Cotta.

HUMBOLDT, Alexander von, 1995 [1814-1825], Personal Narrative of a Journey to the Equinoctial Regions of the New Continent. Londres, Penguin (versão abreviada).

HUMBOLDT, Alexander von, 2007, Pinturas da Natureza: Uma Antologia. Lisboa, Assírio \& Alvim (trad. Gabriela Fragoso).

JAMES, C. L. R., 1963, The Black Jacobins: Toussaint L'Ouverture and the San Domingo Revolution. Nova Iorque, Vintage Books/Random House (versão revista).

KEHLMANN, Daniel, 2005, Die Vermessung der Welt. Reinbek bei Hamburg, Rowohlt.

KOSELLECK, Reinhart, 1989, Vergangene Zukunft: Zur Semantik geschichtlicher Zeiten, Frankfurt am Main, Suhrkamp.

LEIRIS, Michel, 1996 [1934], "L'Afrique fantôme", em Michel Leiris, Miroir de l'Afrique. Paris, Gallimard, 86-887 (org. Jean Jamin).

LEIRIS, Michel, 2011 [1950], "O etnógrafo face ao colonialismo", em Manuela Ribeiro Sanches (org.), Malhas Que os Impérios Tecem: Textos Anti-Coloniais, Contextos Pós-Coloniais. Lisboa, Edições 70, 199-217 (trad. Manuela Ribeiro Sanches).

LEITNER, Ulrike, 1995, "Das Leben eines Literaten, das sind seine Werke": Alexander von Humboldt: von den "Ansichten der Natur" bis zum "Kosmos". Berlim, Berlin-Brandenburgische Akademie der Wissenschaften.

LÉVI-STRAUSS, Claude, 1955, Tristes Tropiques. Paris, Plon.

MALINOWSKI, Bronislaw, 1984 [1922], Argonauts of the Western Pacific: An Account of Native Entreprise and Adventure in the Archipelagoes of Melanesian New Guinea. Prospect Heights, IL, Waveland. 
MALINOWSKI, Bronislaw, 1989, A Diary in the Strict Sense of the Term. Stanford, CA, Stanford University Press (introd. Raymond Firth).

MIGNOLO, Walter, 2011, The Darker Side of Western Modernity: Global Futures, Decolonial Options. Durham, NC, Duke University Press.

PRATT, Mary Louise, 1992, Imperial Eyes: Travel Writing and Transculturation. Londres e Nova Iorque, Routledge.

QUIJANO, Aníbal, 2000, "Colonialidad del poder, eurocentrismo y América Latina”, em Edgardo Lander (org.), Colonialidad del Saber, Eurocentrismo y Ciencias Sociales. Buenos Aires, CLACSO-UNESCO, 201-246.

ROSALDO, Renato, 1993 [1989], Culture and Truth: The Remaking of Social Analysis. Boston, Beacon Press.

RUPKE, Nicolaas A., 2008, Alexander von Humboldt: A Metabiography. Chicago, The University of Chicago Press.

SABOURIN, Eric, 1980, "L'affaire Herzog", Journal de la Société des Américanistes, 67 (1): 441-460, disponível em < http://www.persee.fr/doc/jsa_0037-9174_1980_num_67_1_ $3108>$ (última consulta em junho de 2017).

SAID, Edward W., 1975, Beginnings: Intention and Method. Nova Iorque, Basic Books.

SAID, Edward W., 1995 [1978], Orientalism: Western Conceptions of the Orient. Londres, Penguin.

SAID, Edward W., 2005 [2000], "Reconsiderando a teoria itinerante”, em Manuela Ribeiro Sanches (org.), Deslocalizar a "Europa”: Antropologia, Arte, Literatura e História na Pós-Colonialidade. Lisboa, Cotovia, 25-42 (trad. Manuela Ribeiro Sanches).

SANCHES, Manuela Ribeiro, 1994, “'Diese zarten, fast unsichtbaren Fäden der Arachne’: Das wahrnehmende Subjekt und die Konstituierung von Wahrheit bei Forster”, em Claus Volker Klenke, Jörn Garber e Dieter Heintze (orgs.), Georg Forster in interdisziplinärer Perspektive. Berlin, Akademie Verlag, 133-146.

SANCHES, Manuela Ribeiro, 2005, "Introdução," em Manuela Ribeiro Sanches (org.), Deslocalizar a "Europa": Antropologia, Arte, Literatura e História na Pós-Colonialidade. Lisboa, Cotovia, 7-21.

SANCHES, Manuela Ribeiro, e Adriana Veríssimo SERRÃO (orgs.), 2002, A Invenção do "Homem": Raça, Cultura e História na Alemanha do Século XVIII. Lisboa, Centro de Filosofia da Universidade de Lisboa.

SCHLEGEL, Friedrich, 1985 [1797], “Georg Forster: Fragment einer Charakteristik der deutschen Klassiker”, em Friedrich Schlegel, Schriften zur Literatur. Munique, Deutscher Taschenbuch Verlag, 193-214 (org. Wolfdietrich Rasch).

SMITH, Bernard, 1985, European Vision and the South Pacific, 1768-1850: A Study in the History of Art and Ideas. New Haven e Londres, Yale University Press (2. ${ }^{\mathrm{a}}$ edição).

SPIVAK, Gayatri Chakravorty, 1988, "Subaltern studies: deconstructing historiography”, em Ranajit Guha e Gayatri Chakravorty Spivak (orgs.), Selected Subaltern Studies. Nova Iorque e Oxford, Oxford University Press, 3-32.

SPIVAK, Gayatri Chakravorty, 1995, "Can the subaltern speak?”, em Bill Ashcroft, Gareth Griffiths e Helen Tiffin (orgs.), The Post-Colonial Studies Reader. Londres e Nova Iorque, Routledge, 66-111.

STOCKING JR., George (org.), 1996, Volksgeist as Method and Ethics: Essays on Boasian Ethnography and the German Anthropological Tradition. Madison, WI, The University of Wisconsin Press. 
WILSON, Jason, 1995, "Introduction", em Alexander von Humboldt, Personal Narrative of Journey to the Equinoctial Regions of the New Continent. Londres, Penguin, xxv-lxiv (org. e trad. Jason Wilson).

WULF, Andrea, 2015, The Invention of Nature: Alexander von Humboldt's New World. Londres, John Murray. 